\title{
OSTEOCHONDRODYSTROPHIA DEFORMANS WITH MUCOPOLYSACCHARIDOSIS
}

\author{
BY \\ S. VESTERMARK \\ From the Queen Louise's Children's Hospital, Copenhagen, Denmark
}

(RECEIVED FOR PUBLICATION JULY 8, 1964)

In 1929, Morquio described a peculiar skeletal disease, which he called familial osseous dystrophy. The disease develops gradually after the first year of life and is characterized by dwarfism with short neck, deformed chest with protruding sternum, deformed legs with pronounced genu valgum, and broad flat feet. The skull and face are normal and the intelligence is normal. The disease is often accompanied by muscular weakness. Radiologically, in Morquio's patients the epiphyses of the long bones were deformed with irregular calcifications, and the development of the ossification centres of the carpal and tarsal bones was defective. Only slight changes were found in the spine. The same year Brailsford (1929) described a similar entity, which he called chondro-osteodystrophy, but in his patient radiography showed distinct changes also in the spine, the vertebral bodies being of irregular shape and size with blurred edges and a tongued anterior surface. The disease is now called osteochondrodystrophia deformans, Morquio's disease, or Morquio-Brailsford's disease. In 1926 Silfverskiöld described a disorder with similar radiological changes in the epiphyses and in the spinal column, but the clinical picture was much less peculiar, the patients exhibiting only moderate retardation of growth, moderate thoracic kyphosis, and pronounced varus position of the feet.

The characteristic skeletal changes may vary from very slight lesions which can only be detected radiologically, to gross changes with dwarfism and deformed spinal column (Brailsford, 1948). The most pronounced forms of Morquio-Brailsford's disease offer many points of resemblance to gargoylism (Robinow, 1958), and the question whether Morquio-Brailsford's disease and gargoylism are variants of the same disorder or whether they are two different entities remains to be solved. Some authors state that the radiological skeletal changes in Morquio-Brailsford's disease and gargoylism are indistinguishable (Eichenberger, 1954), and clinically there exist transitional forms, i.e. Morquio-Ullrich's disease, between the two entities (Wiedemann, 1954); hence it has been suggested that the various entities be united under the name of gargoylism (Eichenberger, 1954). However, this term seems inapposite, since gargoylism refers to the grotesque appearance seen only in the most severe case. Others maintain that gargoylism and Morquio-Brailsford's disease are two different disorders and that MorquioUllrich's disease comes under neither (Zellweger, Ponseti, Pedrini, Stamler, and von Noorden, 1961). In gargoylism, accumulation of acid mucopolysaccharides with a high content of hexosamines in brain, liver, bones, and other organs, and increased urinary excretion of acid mucopolysaccharides has been demonstrated. In Morquio-Ullrich's disease deposits of acid mucopolysaccharides in bone tissue and increased urinary excretion of acid mucopolysaccharides were also found, but the excreted mucopolysaccharides were different from those excreted in gargoylism (Zellweger et al., 1961; Dyggve, Melchior, and Clausen, 1962).

Such biochemical differences as have hitherto been demonstrated between gargoylism, Morquio-Brailsford's disease, and Morquio-Ullrich's disease are hardly sufficient to decide that they are three different entities.

This paper reports a study of a family consisting of five members, all of whom had increased urinary excretion of mucopolysaccharides, two out of three children furthermore having a slight degree of osteochondrodystrophia deformans.

\section{Method}

The technique used for demonstrating acid mucopolysaccharides has previously been described by Dyggve $e t$ al. (1962). The urine is collected for 24 hours and concentrated 100 times by vacuum dialysis. After electrophoresis on filter paper the patterns are stained with Alcian blue and compared with the patterns obtained from standard preparations of hyaluronic acid, chondroitin sulphate, and heparin. 


\section{Case Reports}

The father was born in 1907. About 20 years ago he was admitted to hospital for examination because of muscle weakness. He now walks heavily and with difficulty and has to lean on the furniture. Radiography of chest shows an arcuate thoracic kyphosis with slightly wedge-shaped vertebral bodies (Fig. 1), while that of the knees shows slightly irregular joint surfaces and formation

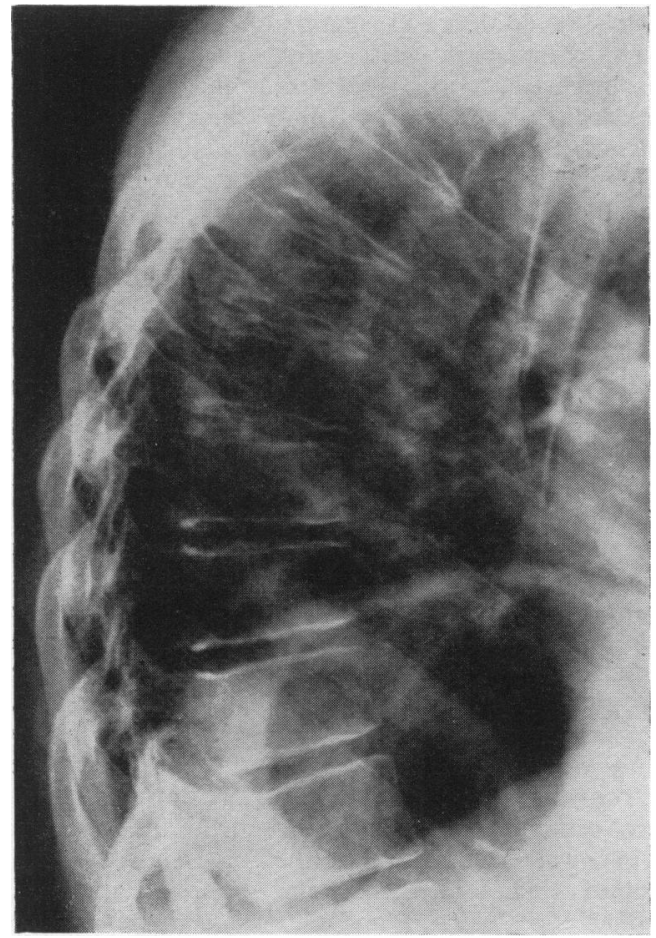

FIG. 1.-The spine of the father, aged 56. There is kyphosis with small osteophytes in the upper part.

of osteophytes. The urine contains acid mucopolysaccharides which by electrophoresis appear to consist of one fraction with a rate of migration similar to that of chondroitin sulphate and one fraction with a lower rate of migration.

The mother was born in 1925. She has no symptoms. Her height and appearance are normal. Radiological examination of the spine, wrists, hips, and pelvis shows nothing abnormal. The serum levels of calcium, phosphorus, and alkaline phosphatase are normal. In the urine, acid mucopolysaccharides are present, electrophoresis revealing also in this case one fraction with a rate of migration similar to that of chondroitin sulphate, and one fraction with a lower rate of migration.

Case 1. The first child is a boy who was born in 1949. Since the age of 2 years his gait has been poor, with varus feet. On examination in 1963 he was $17 \mathrm{~cm}$. below the

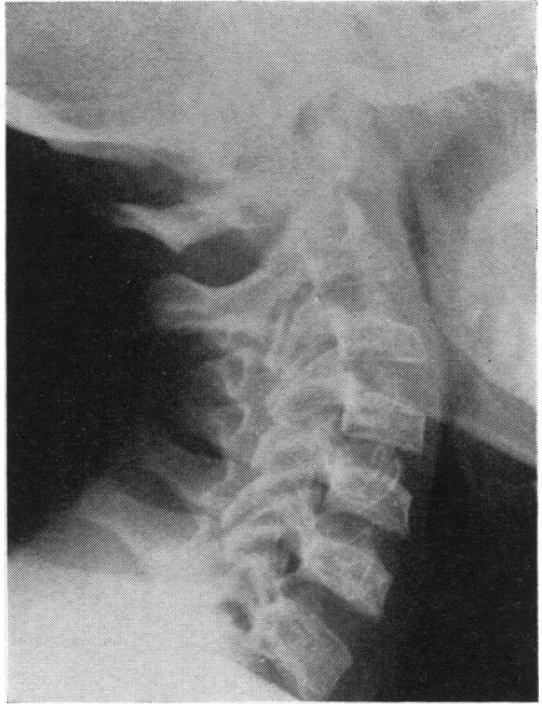

Fig. 2.-Case 1. The cervical part of the spine with flattened bodies.

expected height. He is not short necked and his face is normal. The chest is slightly deformed with a prominence of the right side but no protrusion of the sternum. There is increased lumbar lordosis and a moderate arcuate thoracic kyphosis. The upper limbs show hyperextension of the terminal phalangeal joints and Heberden's nodes. The lower limbs show moderate atrophy of the femoral muscles, but no pareses. The feet show pronounced cavovarus deformity and prominence of the lateral malleoli. Knee and ankle reflexes are absent.

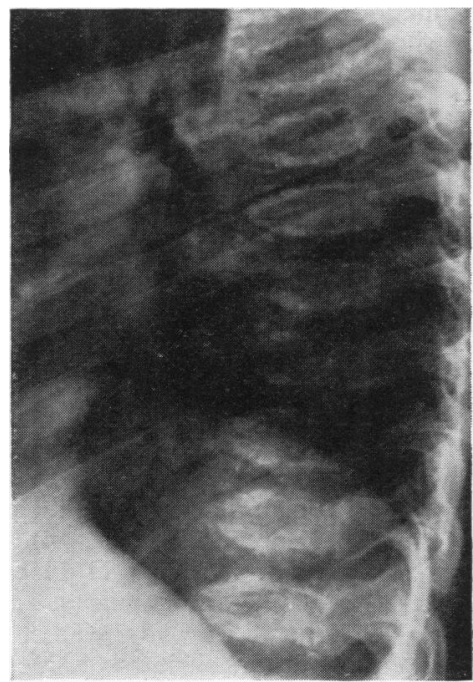

Fig. 3.-Case 1. The thoracic corpora are flattened with blurred edges and wedge-shaped anterior surfaces. 


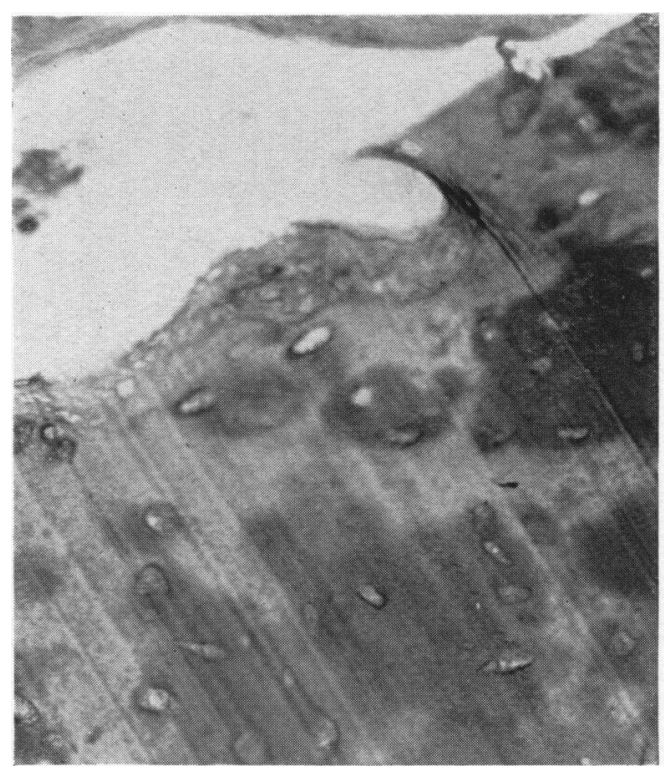

Fig. 4.-Case 1. Biopsy from the iliac crest. The darkly stained areas indicate a high content of acid mucopolysaccharides. (Alcian blue and periodic acid-Schiff. $\times 100$.)

The gait is somewhat clumsy but not ataxic. Plantar reflexes normal. The skin of fingers and toes is thick and rough. Radiological examination of the spine reveals pronounced changes in almost all vertebral bodies which are flat with irregular blurred edges and wedge-shaped anterior surfaces (Figs. 2 and 3). Radiological examination of hip joints and pelvis reveals increase in width of the femoral neck and irregular skeletal structure. Radiological examination of skull, chest, upper limbs, and lower limbs shows nothing abnormal. Bone age, 11 years at chronological age 14. Intelligence and hearing are normal. Eye examination shows slight hypermetropia and red-green colour blindness, but no corneal opacities. Electromyography shows degeneration of motor units in tibialis anterior, while the rate of conduction is normal. Skin biopsy reveals nothing abnormal. Biopsy from tibialis anterior muscle shows partially atrophied muscle fibres in some regions and completely atrophied fibres in others, with abundant interstitial fatty tissue, i.e. neurogenic muscular atrophy. Bone biopsy from the iliac crest shows cartilaginous fragments with irregularly proliferating small islands of normal cartilage cells, bordering on regions with scarce and irregular calcification and with few osteoblasts. Cartilage matrix shows areas of pronounced Alcian blue staining, indicating the presence of mucopolysaccharide (Fig. 4). Proteinbound iodine and tri-iodothyronine in blood, serum proteins, electrolytes, GO-transaminases, and GPtransaminases, lactic acid dehydrogenase, creatine phosphokinase, and serum citric acid are normal. Serum calcium is normal, but serum phosphorus is low $(2.6 \mathrm{mEq} / \mathrm{l}$.), and alkaline phosphatase slightly increased
(32.6 K.A. units). Serum immunoelectrophoresis is normal. Wasserman reaction negative. Urinary excretion of 17-ketosteroids normal. Excretion of amino acids normal. Creatine/creatinine index $131 \%$. In the urine there is increased excretion of acid mucopolysaccharides with a rate of migration similar to that of chondroitin sulphate.

Case 2. The second child is a girl, born in 1951. She has no symiptoms and her height and appearance are normal. Tendon reflexes normal. Fractional serum protein, serum citric acid, serum calcium, and creatine phosphokinase normal. Serum phosphorus slightly decreased $(2.7 \mathrm{mEq} / 1$.$) ; alkaline phosphatase slightly$ increased (27 K.A. units). Radiolngical examination of skull, spine, and limbs shows nothing abnormal. In the urine there is increased excretion of acid mucopolysaccharides, which by electrophoresis are identified as one fraction with a rate of migration similar to that of chondroitin sulphate and one fraction with a slower rate of migration.

Case 3. The third child is a girl who was born in 1954. She is $13 \mathrm{~cm}$. shorter than normal for her age. Her face is normal and she is not short necked. There is an increased lumbar lordosis but no kyphosis, and her chest is not deformed. There is hyperextension of the terminal phalangeal joints, and Heberden's nodes are present. The skin of her fingers is somewhat thick and rough. No muscular atrophy or pareses are present. The knee and ankle reflexes cannot be elicited. Plantar reflexes are normal. Her feet show rather pronounced cavovarus deformity with protrusion of the lateral malleoli. Eye examination reveals a slight hypermetropia, but no corneal opacities. Hearing and intelligence are normal. Electromyography of tibialis anterior, normal. Radiological examination of the skull and the limbs, normal. Radiological examination of the spine shows flattened vertebral bodies with irregular bone structure and irregular edges (Figs. 5 and 6). Wassermann reaction, negative. Serum proteins, GO-transaminases, GPtransaminases, creatine phosphokinase, lactic acid dehydrogenase, serum amino acids, and citric acid are normal. Serum calcium, normal, phosphorus somewhat low $(2.7 \mathrm{mEq} / \mathrm{l}$.), and alkaline phosphatase slightly increased (29 K.A. units). Serum immunoelectrophoresis normal. Creatine/creatinine index $133 \%$ Examination of urine shows increased excretion of acid mucopolysaccharides with a rate of migration similar to that of chondroitin sulphate.

Summarizing the urinary mucopolysaccharide findings: in urine from the father, the healthy mother, and the healthy sister, an electrophoretic fraction with the same rate of migration as chondroitin sulphate, together with an unidentified fraction with a somewhat lower rate of migration are present, while urine from the two children with skeletal affection contains chondroitin sulphate only. In all five cases the acid mucopolysaccharide fractions are weak, but distinctly pathological by comparison with normal urine. No quantitative determination of the acid mucopolysaccharides has been possible. 


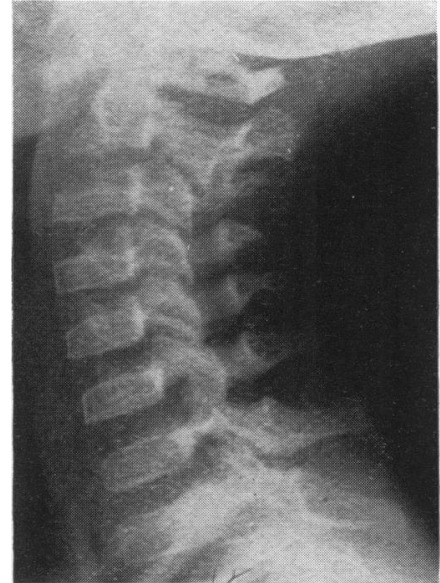

FIG. 5.-Case 3. The bodies of the cervical vertebrae are flattened.

\section{Discussion}

The radiological changes of the spine in our two patients are characteristic of osteochondrodystrophia deformans (Brailsford, 1948). The father has an

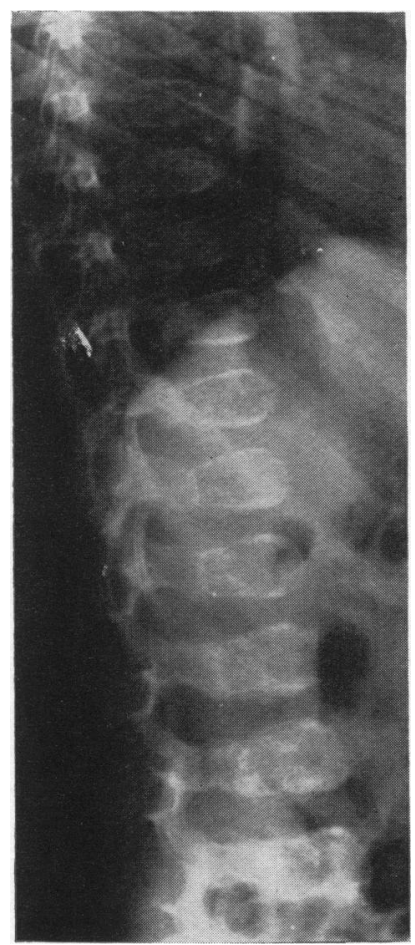

FIG. 6.-Case 3. The bodies of the thoracic vertebrae are flattened with slightly wedge-shaped anterior surfaces. The lumbar vertebrae show irregular edges. arthrosis deformans. Whether he has previously had osteochondrodystrophy is not known, but in some familial cases of osteochondrodystrophy the parents have sometimes had arthrosis deformans (Guldager, 1945; Silfverskiöld, 1926). Both our patients are somewhat smaller than normal for their ages, with slender extremities and increased lumbar lordosis, but their faces are normal and they are of normal intelligence. The neck is not shortened and there are no corneal opacities. These findings are consistent with the difficulty of detecting the slighter cases clinically. In our two patients the creatine/ creatinine index is slightly raised, but the enzymatic activity in the serum is normal. In the elder patient there is a moderate symmetrical muscular atrophy of the thighs. It is not clear whether the muscle disorder is myogenic or neurogenic, since the younger patient has a normal electromyogram, while muscle biopsy and electromyogram in the elder patient point towards a neurogenic affection. Both patients have symmetrical areflexia on their lower limbs, favouring a neurogenic affection, though it is strange that no other neurological degeneration symptoms can be detected. Osteochondrodystrophia deformans, however, seems only occasionally to be accompanied by neurological degeneration; Einhorn, Moore, Ostrum, and Rowntree (1941) described 3 patients with pronounced neurological symptoms and ascribed these to cord compression in the spinal canal, which was confirmed in one of the patients coming to necropsy (Einhorn, Moore, and Rowntree, 1946).

The elder of our patients exhibits delayed development of ossification centres, but in neither patient do the blood analyses give any evidence of endocrine, renal, or hepatic disorder. Alkaline phosphatase is slightly raised and serum phosphorus reduced both in the two patients and in their healthy sister. A few other authors have previously demonstrated raised alkaline phosphatase in osteochondrodystrophia deformans (Andersen, 1937; Crawford, 1939; Whiteside and Cholmeley, 1952), but in most cases serum calcium, phosphorus, and alkaline phosphatase were normal.

Bone biopsy from the elder patient shows irregular arrangement of cartilagenous cells. The basic substance stains strongly, but irregularly with Alcian blue. Similar changes have been described previously in Morquio-Brailsford's disease (Shelling, 1957). In Morquio-Ullrich's disease Zellweger et al. (1961) found changes which partly correspond to those described above and partly resemble the changes seen in gargoylism.

The mucopolysaccharides found in our patients are not quite identical with those found in patients 
with Morquio-Ullrich's disease (Clausen, Dyggve, and Melchior, 1963; Zellweger et al., 1961), but since few quantitative and qualitative studies into the excretion of acid mucopolysaccharides in Morquio-Brailsford's disease and Morquio-Ullrich's disease have been published, the importance of this finding cannot be assessed. Increased urinary excretion of acid mucopolysaccharides is a nonspecific mesenchymal reaction (Hauss, JungeHülsing, and König, 1962), but when it is associated with an accumulation of acid mucopolysaccharides in the bone tissue, as in one of our patients, it must be presumed that the disease is due to an inborn error of metabolism as in gargoylism and Morquio-Ullrich's disease.

Robinow (1958) states that the heredity in osteochondrodystrophy may be autosomal recessive or autosomal dominant, and that these two forms of heredity represent two different diseases. Looking at the clinical symptoms alone the pattern of disease in our family implies an autosomal dominant inheritance, but if we take the pathological excretion of acid mucopolysaccharides into consideration the pattern implies a recessive autosomal inheritance with the mother and the normal daughter as carriers. This latter conclusion seems not unjustified; a recessive autosomal inheritance would provide a link with gargoylism and with Morquio-Ullrich's disease.

\section{Summary}

A family with increased urinary excretion of acid mucopolysaccharides is described. In two of the cases radiological changes in the spine were found, like those of Morquio-Brailsford's disease, though the clinical appearances of the patients are normal. Bone biopsy from one of the two patients showed increased content of acid mucopolysaccharides. It is concluded that even mild forms of MorquioBrailsford's disease are due to an inborn error of metabolism as in Morquio-Ullrich's disease and gargoylism.

\section{REFERENCES}

Andersen, T. (1937). Et tilfælde af typisk chondrodystrofi. Ugeskr. Laeg., 99, 169.

Brailsford, J. F. (1929). Chondro-osteo-dystrophy. Amer. J. Surg., 7, 404.

- (1948). The Radiology of Bones and Joints. Churchill, London.

Clausen, J., Dyggve, H. V., and Melchior, J. C. (1963). Mucopolysaccharidosis. Paper electrophoretic and infra-red analysis of the urine in gargoylism and Morquio-Ullrich's disease. Arch. Dis. Childh., 38, 364.

Crawford, T. (1939). A case of Morquio's disease. ibid., 14, 70.

Dyggve, H. V., Melchior, J. C., and Clausen, J. (1962). MorquioUllrich's disease. An inborn error of metabolism? ibid., 37, 525.

Eichenberger, K. (1954). Kann die Dysostosis Morquio als selbständiges Krankheitsbild vom Gargoylismus abgetrennt werden? Ann. paediat. (Basel), 182, 107.

Einhorn, N. H., Moore, J. R., Ostrum, H. W., and Rowntree, L. G. (1941). Osteochondrodystrophia deformans (Morquio's disease). Amer. J. Dis. Child., 61, 776.

_- _ and Rowntree, L. G. (1946). Osteochondrodystrophia deformans (Morquio's disease). ibid., 72, 536.

Guldager, A. (1945). Osteochondrodystrophia deformans. Silfverskiöld-Morquio's sygdom. Ugeskr. Laeg., 107, 327.

Hauss, W. H., Junge-Hülsing, G., and König, F. (1962). Über das Vorkommen von Veränderungen des Mucopolysaccharidstoffwechsels in der Klinik. 1. Klinische Beobachtungen zur unspezifischen Mesenchymreaktion. Med. Welt (Berl.), 2, 2371.

Morquio, L. (1929). Sur une forme de dystrophie osseuse familiale. Arch. Méd. Enf., 32, 129.

Robinow, M. (1958). Morquio's disease. Clin. Orthop., 11, 138.

Shelling, D. H. (1957). Osteochondrodystrophia deformans. In Brenneman's Practice of Pediatrics, Vol. 4, Chap. 29. Prior, Hagerstown, Maryland.

Silfverskiöld, N. (1926). Sur la question de l'achondroplasie atypique et de sa forme périphérique. Acta radiol. (Stockh.), 5, 223.

Whiteside, J. D., and Cholmeley, J. A. (1952). Morquio's disease. A review of the literature with a description of four cases. Arch. Dis. Childh., 27, 487.

Wiedemann, H.-R. (1954). Ausgedehnte und allgemeine erblich bedingte Bildungs- und Wachstumsfehler. Mschr. Kinderheilk., $102,136$.

Zellweger, H., Ponseti, I. V., Pedrini, V., Stamler, F. S., and von Noorden, G. K. (1961). Morquio-Ullrich's disease. J. Pediat. 59, 549. 